\title{
A Construção de Estratégias: um estudo de caso no setor avícola
}

\author{
Ricardo César Alves ${ }^{1}$ \\ Humberto Elias Garcia Lopes²
}

\section{Resumo}

Este artigo tem como campo de estudo o processo de formulação de estratégias em uma empresa do setor avícola do Estado de Minas Gerais. O objetivo foi verificar se tal empresa construía suas estratégias de forma deliberada - apoiandose na concepção clássica de estratégia - ou de forma emergente, como resposta às movimentações do ambiente. Metodologicamente, o trabalho foi de caráter qualitativo, com objetivo descritivo e apoiado em um estudo de caso, no qual oito gestores da empresa Alfa foram entrevistados por meio de um roteiro semiestruturado. A análise do conteúdo das entrevistas mostra que a empresa Alfa, ainda tem como padrão formular estratégias como repostas ao ambiente, apesar de se esforçar para implementar processos deliberados de construção. Os planos e processos racionais de construção de estratégias, apesar de serem considerados de grande importância pelos entrevistados, não se mostraram presentes no cotidiano da empresa. Os resultados desta pesquisa são relevantes para a área de Administração devido a dois aspectos: o primeiro deles é indicar que a estratégia - no caso da empresa pesquisada - é formulada principalmente com base em reações ao ambiente e não como fruto de um processo racional de análise e definição; o segundo é indicar que os gestores conhecem a importância desses processos mais racionais de elaboração de estratégias, mas que fatores diversos impedem que eles sejam aplicados na prática.

Palavras-chave: Estratégia. Competitividade. Formulação. Tomada de decisão. Resultados.

\footnotetext{
${ }^{1}$ Doutorando em Administração pela UFLA. Professor da PUC Minas. Endereço: Rua Maria Heilbuth Surette, 484/401 - Buritis - Belo Horizonte-MG-Brasil. CEP 30575-100.E-mail: rialves@pucminas.br.

${ }^{2}$ Doutor em Administração pela UFMG. Programa de Pós-Graduação em Administração da PUC Minas. Endereço: Av. Itaú, 525 - Dom Cabral - Belo Horizonte - MG - Brasil. CEP 30535-012.E-mail: pesquisagemitec@yahoo.com.br.

Artigo recebido em: 15/08/2008. Aceito em: 25/11/2009. Membro do Corpo Editorial Científico responsável pelo processo editorial: Emerson Antônio Maccari.
} 


\section{Introdução}

A proposta deste trabalho é analisar a construção das estratégias de uma grande empresa produtora de carne de frango em Minas Gerais. A pesquisa buscou obter informações que pudessem apresentar, de maneira empírica, a forma pela qual essa empresa construía suas estratégias, verificando se elas eram formadas segundo um planejamento formal ou uma inovação adotada informalmente.

A literatura mostra que essa questão está envolta em muitas ambiguidades. Isso porque os estudos sobre a estratégia referem-se a um grande número de teorias, escolas de pensamento e modelos de estratégia, existindo mais desacordos do que acordos sobre o que são ou devem ser os processos de formação de estratégias (MINTZBERG; AHLSTRAND; LAMPEL, 2000).

O segmento específico deste estudo é a avicultura de corte, responsável pelo mercado de carne de frango, componente importante da indústria alimentícia brasileira. De acordo com a União Brasileira da Avicultura - UBA (2004/2005) houve aumentos significativos na produção de carne de frango no Brasil, aumentando a produção de 2.055.287 toneladas, em 1989, para 9.297.151 toneladas, em 2005, um avanço acima dos 350\%. Esse avanço é ainda mais significativo quando se considera a evolução do consumo per capita brasileiro da carne de frango, que fechou o ano de 2005 com uma média anual de $35,48 \mathrm{~kg}$ contra $12,73 \mathrm{~kg}$ no ano de 1989 , o que demonstra um crescimento superior a $170 \%$. Enquanto isso, a carne bovina - o tipo mais consumido pela população brasileira - teve seu consumo per capita ampliado pouco mais de $5 \%$ no mesmo período, passando de $33,8 \mathrm{~kg} / \mathrm{ano}$ em 1989 para 35,9 kg/ano em 2005.

Esses dados demonstram a evolução do segmento, o que influencia diretamente as empresas que compõem o setor. Nas últimas décadas, as empresas do setor avícola brasileiro têm realizado constantes investimentos em tecnologia (visando maior produtividade) e na expansão da capacidade produtiva (buscando economias de escala) para se adequarem às necessidades do mercado. Tais investimentos estão relacionados com as estratégias de competição adotadas pelas empresas avícolas (MATIAS; MEIRELLES; CALDEIRA, 2002).

Essa evolução do setor leva as empresas a desenvolverem ações distintas para participarem do mercado. De acordo com Schardong e Gonçalo (2005), percebe-se claramente que a indústria avícola brasileira é composta 
por empresas que possuem diferentes estratégias de competição. Tais diferenças estão relacionadas a fatores como dimensão de mercado, tipos de produtos ofertados, canais de distribuição, tecnologia empregada nos processos produtivos e de informação, políticas de comunicação e perfil de gerência. Para Meirelles (2003), as estratégias são dependentes de variáveis que, muitas vezes, são impossíveis de se determinar com precisão, cabendo à organização fazer suas escolhas estratégicas e buscar os resultados que lhe interessam.

Essas diferenças de escolhas estratégicas podem ser influenciadas pelos processos por meio dos quais se formam as estratégias nas organizações. Segundo Mintzberg e Waters (1985), as empresas adotam processos distintos, fazendo com que a construção das estratégias possa ocorrer em duas direções: uma deliberada e outra emergente. A diferença fundamental entre a estratégia deliberada e a emergente é que, enquanto a primeira enfatiza o planejamento, a direção e o controle, partindo do pressuposto de que as ações deliberadas serão necessariamente realizadas, a última permite a noção de "aprendizado estratégico", ou seja, as empresas se desenvolvem à medida que o ambiente competitivo gera novos cenários de atuação.

De acordo com Whittington (2004), tradicionalmente os estudos sobre estratégia valorizam o desempenho e a vantagem competitiva da empresa, porém, é importante analisar o processo que se utiliza para buscar os resultados, ou seja, como as ações estratégicas são montadas. Mintzberg, Ahlstrand e Lampel (2000) argumentam que a formação da estratégia leva, primeiro, a modelos de diferentes paradigmas, mas que convergem, em um estado futuro, para fins conciliatórios e de interação. Segundo esses autores, a formação da estratégia é um desígnio arbitrário, uma visão e um aprendizado intuitivo, que envolve tanto transformação quanto perpetuação. Como tal, ela deve englobar cognição individual e interação social, cooperação e conflito, com todas as suas complexidades decorrentes.

Segundo Meirelles (2003), diferentes modelos de formação e implementação de estratégias são importantes para uma organização que enfrenta desafios complexos. Para o autor, há momentos em que um processo planejado e cuidadosamente controlado seria eficaz, enquanto, em outros contextos, um modelo mais flexível, emergente, poderia gerar melhores resultados.

Nesta pesquisa, foi utilizado como referência o Estado de Minas Gerais, quinto maior produtor brasileiro de carne de frango (ABEF, 2009). Definiuse como foco de pesquisa as empresas de grande porte - de acordo com a 
classificação do SEBRAE (2008/2009), produtoras de carne de frango. A escolha desse segmento de empresa é justificada por se tratar de corporações que possuem recursos suficientes para buscar assessoria de organizações desenvolvedoras de planos estratégicos e outras formas de deliberações estratégicas e por estarem entre as lideranças setoriais.

\section{Revisão da Literatura}

O objetivo desta seção é fazer uma revisão dos principais trabalhos sobre estratégia nas organizações, visando um entendimento mais aprofundado da base teórica que norteou esta pesquisa. Para isso, foram abordados os conceitos de estratégia, suas escolas e os processos a ela relacionados.

\subsection{A Estratégia nas Organizações}

O crescente dinamismo e a competição encontrados no ambiente de negócio vêm criando novas formas de organização e envolvimento dos diversos agentes econômicos, sociais e culturais, ao mesmo tempo em que induzem a criação e a consolidação de mecanismos e estilos de gestão adaptados às novas necessidades organizacionais (SOBANSKI, 1995). De acordo com Ribeiro, Rezende e Rezende (2000), o grande desafio do gestor passa pela compreensão do comportamento das firmas, dos fatores que direcionam as estratégias empresariais e explicam as estruturas de mercado.

Mas, afinal, o que significa a estratégia? Como as empresas percebem $e$ utilizam as estratégias? Whittington (2002) adverte que muitos consultores e teóricos entram em contradição já na definição do que é e do que não é estratégia. Mintzberg (2001) polemiza ainda mais a discussão ao afirmar que a estratégia é um termo definido de uma maneira e utilizado de outra. Uma evidência a favor disso é o fato de que ela costuma ser utilizada em referência às transações rotineiras das organizações. Embora tais transações sejam relevantes no contexto organizacional, não se deve tratar processos operacionais e estratégia como sinônimos (PORTER, 1996).

Considerando Ansoff e Mcdonell (1993) e Porter (1989), pode-se definir a estratégia como um conjunto de padrões e comportamentos direcionados à orientação de uma organização para alcançar uma vantagem competitiva, 
através da diferenciação de produtos e serviços oferecidos ao mercado. Meirelles (2003, p. 40) acrescenta ainda que

[...] estratégia é a criação de uma posição competitiva exclusiva e valiosa, envolvendo um conjunto diferente $e$ compatível de atividades; [...] é exercer opções excludentes na competição; é escolher o que fazer, mas fundamentalmente o que não fazer.

Ao analisar as orientações teóricas que abordam o conceito de estratégia, encontram-se várias lacunas e contradições entre as visões dos diversos autores. Contradições que estão nas abordagens que envolvem racionalidade e decisão, força do ambiente, evolução do mercado, competências essenciais etc. Ao mesmo tempo, encontra-se também uma relativa convergência na afirmativa de que o campo da estratégia na administração envolve o estudo dos processos de escolha e decisão nos níveis macro-organizacionais, ou seja, as decisões e ações que impactam o conjunto da organização, a formação de padrões de conduta, a adequação da organização e seus processos internos ao seu ambiente de atuação e o posicionamento competitivo de uma empresa, dentre outros (PORTER, 1989; ANSOFF; MCDONELL, 1993; MINTZBERG; AHLSTRAND; LAMPEL, 2000; MEIRELLES, 2003).

Apesar das dificuldades para definir inequivocadamente o termo estratégia, pode-se dizer que tal termo diz respeito a decisões e ações que têm impacto sobre o conjunto da organização, lidam com a adequação entre esta e o ambiente de atuação, é de natureza complexa e envolve aspectos de conteúdo e processo (MEIRELLES, 2003). Nesse sentido, fazer estratégia relaciona-se ao conhecimento de onde e quando essa interação ocorre no tempo e espaço, reunindo as características básicas de outras áreas da administração para formar os administradores estratégicos (WILSON; JARZABKOWSKI, 2004).

\subsection{As Escolas e as Abordagens da Estratégia}

Para se analisar o processo estratégico de uma organização é necessário conhecer os atores e as dinâmicas envolvidas nas escolhas e definições dos rumos organizacionais, os papéis e funções de executivos, gerentes, áreas funcionais, diretorias, conselhos e mesmo alguns outros grupos de interessados, tais como supridores de recursos financeiros, outros fornecedores, clientes, governo etc. (MEIRELLES, 2003). 
Whittington (2004b) define o caminho dos estudos em estratégia nas organizações. Para ele, não se deve procurar nas empresas o conceito de estratégia e sim como ela é formada e trabalhada. Deve-se pesquisar onde e como a atividade de criação e administração de estratégia realmente é feita. Quem realiza essa atividade? Quais as competências necessárias a essa atividade e como são adquiridas? Quais as ferramentas comuns e as técnicas de criação e administração de estratégias? Como os resultados são divulgados, utilizados e monitorados? Portanto, compreender a estratégia na organização não significa, necessariamente, conceituar ou criar definições e sim entender o processo interativo entre pessoas, ambiente, organização e estratégia, considerando-a como um amplo campo de atividade social, cujas práticas são importantes para a sociedade como um todo (WHITTINGTON, 2004a).

Esse autor apresenta ainda a estratégia dividida sob quatro abordagens distintas. A primeira é a clássica, baseada no planejamento racional para formulação e desenvolvimento estratégico. A abordagem enfatiza a necessidade da análise racional, a distinção entre concepção e execução e o compromisso com a maximização do lucro. A segunda é a evolucionista, que se apoia na evolução biológica como modelo para compreender o mercado, em que a natureza dinâmica e competitiva dos agentes econômicos rejeita o planejamento como peça fundamental para o desenvolvimento e a sobrevivência organizacional. A terceira é a abordagem processualista, cuja característica é enfatizar o processo e acreditar que o desenvolvimento da organização está diretamente ligado à atuação organizacional e à sua relação com os mercados. A última abordagem é denominada de sistêmica, que considera os fins e os meios da estratégia como ligados às culturas, aos poderes, às características sociais, políticas e econômicas dos sistemas sociais dos locais onde ele se desenvolve. Essa abordagem considera que o estrategista deve estar inserido dentro do contexto social das empresas e de seus concorrentes, para que possa entender o cenário que está a sua volta.

A escola clássica é formada pelo direcionamento de processos planejados e uma busca constante pela maximização do lucro. Já a escola sistêmica utiliza os processos deliberados, mas buscando resultados plurais e não apenas a maximização do lucro. Dentro das perspectivas de processos emergentes, a escola evolucionária distingue-se da processualista por orientar sempre o máximo lucro, enquanto os processualistas utilizam as estratégias de forma emergente, mas são orientados a resultados plurais, ou seja, não apenas o lucro, mas melhorias estruturais, processos, imagem e outros. 
Mintzberg, Ahlstrand e Lampel (2000) vão além dessa classificação ao definir dez escolas do pensamento estratégico, cada uma com concepções diferenciadas em relação ao planejamento, aos aspectos específicos de formulação e à integração das ações estratégicas. A primeira é a escola do design, que compreende o processo de formação de estratégia como uma atividade baseada na razão, em que se busca a adaptação da organização e de seus pontos fortes e fracos ao ambiente de mercado. A segunda é a escola do planejamento, relacionada à escola de design e defensora da utilização de processos planejados formalmente e com utilização de variadas formas de monitoramento de resultados. Já a escola do posicionamento, também de caráter normativo, sustenta que para a formação da estratégia, é de fundamental importância a escolha do posicionamento competitivo, definido a partir do profundo conhecimento do ambiente de atuação.

A quarta escola, chamada de empreendedora define a estratégia como informal e sustentada pela visão dos líderes. Assim, há sempre espaço para a criação e inovação. Essa escola valoriza fatores antes desprezados como intuição, julgamento, experiência etc. A quinta escola é a cognitiva, que entende a formação da estratégia como um processo mental que depende, portanto, de como os dirigentes compreendem a realidade e a organização, ou seja, "a estratégia ancora-se nos mapas ou esquemas mentais e processos cognitivos que habitam as mentes dos estrategistas" (MEIRELLES, 2003, p. 54). A escola de aprendizagem aponta para o surgimento da estratégia por meio do aprendizado ao longo do tempo. Para ela, a estratégia emerge a partir de processos de tentativa e erro.

Para a escola do poder, as estratégias dependem claramente da negociação entre os grupos e indivíduos e o poder estabelecido de cada participante. Duas grandes linhas são observadas nessa escola: aquela que aborda o poder entre os participantes da empresa (poder interno) e o poder que envolve as relações da empresa com seu ambiente macro (externo). Para a escola culturalista, a estratégia fundamenta-se nas crenças, nos valores e nas interpretações compartilhadas pelos membros da organização. Portanto, o conhecimento adquirido ao longo do tempo pela empresa não é descartado no processo. O enfoque ambiental aponta para o esforço da organização para reagir às oscilações advindas do ambiente, o que demonstra o papel de destaque do ambiente no processo de formação de estratégia. A escola da configuração busca trazer, à luz da teoria, a integração e o perfil conciliatório das escolas de estratégias. Para Meirelles (2003), a escola da configuração faz 
uma conciliação das nove escolas e enfatiza o caráter transitório e contextual das estratégias, por meio do delineamento de estratégias ou configurações. Assim,

[...] cada escola em sua época, em seu lugar. Portanto, a escola de configuração, difere de todas as outras em um aspecto fundamental: ela oferece a possibilidade de reconciliação, uma maneira de integrar as mensagens das outras escolas (MINTZBERG; AHLSTRAND; LAMPEL, 2000, p. 222).

Por sua vez, Volberda (2004), com uma análise mais objetiva, aponta três perspectivas em gestão estratégica: clássica, moderna e pós-moderna. Para a perspectiva clássica, a estratégia é desenvolvida com base em planos e objetivos previamente definidos: "estratégia é um processo de planejamento deliberado, iniciado pela cúpula, baseado em análises racionais e focado no desenvolvimento de uma estratégia consistente" (VOLBERDA, 2004, p. 34). Já dentro da visão moderna, a estratégia emerge de vários fatores que compõem o complexo ambiente de mercado:

[...] a estratégia, na perspectiva moderna, é apresentada como um processo complexo, desconexo e desordenado (emergente), ao redor do qual se confrontam fatores concorrentes (VOLBERDA, 2004, p. 36).

Assim, o racionalismo da visão clássica perde sentido e deixa de ser o foco dos principais estudiosos de estratégia. Por fim, o autor apresenta a visão pós-moderna da gestão estratégica. Nesse caso, o autor aponta que a estratégia é compreendida por esquemas estratégicos ou por modelos de referência que permitem a adaptação da organização ao ambiente e às necessidades da própria organização. Assim, uma organização está sempre preparada a responder às oscilações ambientais.

Esta seção apresentou uma visão mais ampla sobre a diversidade de caminhos que devem ser trilhados pelas organizações ao se engajarem no desenvolvimento estratégico. Na próxima seção, será apresentada uma discussão específica sobre o processo de construção da estratégia nas organizações. 


\subsection{O Processo de Construção de Estratégia}

As principais discussões sobre estratégia baseiam-se no papel do planejamento no contexto organizacional e no processo de formulação deles. Os principais conceitos de estratégia vão de encontro à definição de padrões, planos de ações e deliberações que orientem as intenções das organizações. Mintzberg (1998) afirma que o estrategista é sempre reconhecido como um visionário, planejando para que outros implementem. Outra abordagem o considera

[...] como um reconhecedor de padrões, um profissional em constante aprendizagem que gerencia um processo no qual estratégias e visões podem emergir, assim como ser deliberadamente concebidas (MINTZBERG, 1998, p. 432).

Meirelles (2003) apresenta, ainda, o cenário encontrado nos estudos em estratégia ao destacar que existem duas correntes de autores: a formada pelos que tratam a estratégia como um processo estritamente formal, operacionalizado por atores racionais e economicamente orientados e a que é composta por aqueles que negam a existência de qualquer racionalidade a priori direcionando as decisões.

Pettigrew (1977) alerta para a importância da distinção entre a formação de estratégias e a formulação estratégica. A formação ou construção da estratégia é vista pelo autor como um processo contínuo de desenvolvimento de estratégias organizacionais, enquanto a formulação estratégica se caracteriza como um processo intencionalmente construído, em que as decisões são feitas, tanto por pessoas como pelos grupos intraorganizacionais.

Mintzberg e Waters (1985) ressaltam a formação da estratégia no âmbito da organização. Eles afirmam que a formação das estratégias ocorre em duas direções: uma deliberada e outra emergente. A diferença fundamental entre a estratégia deliberada e a emergente é que, enquanto a primeira enfatiza o planejamento, a direção e o controle, fazendo com que intenções sejam realizadas, a última permite a noção de "aprendizado estratégico", ou seja, as empresas se desenvolvem à medida que o ambiente competitivo gera novos cenários de atuação. Uma estratégia pode emergir como resposta a uma situação em evolução ou pode ser introduzida, deliberadamente, por meio de um processo de formulação seguido de implementação. As estratégias emer- 
gentes são ações praticadas na dinâmica das organizações sem terem sido planejadas. Posteriormente, uma vez bem-sucedidas, passam a se integrar ao esforço de planejamento da instituição (MINTZBERG, 1998). Para Saraiva (2004), a estratégia seria originada a partir do contexto, entendendo ele como o conjunto de variáveis formado pelo tempo, pela cultura organizacional, pelo seu ambiente e pelo seu nível de estabilidade, as atividades, a estrutura e o aparato tecnológico da organização e, ainda, sua liderança e sistema político interno. (SARAIVA, 2004)

Contudo, um dos pontos críticos no processo de implementação do plano estratégico, ou da estratégia, é a diferença entre planejamento e pensamento estratégico. Como planejamento estratégico refere-se a uma programação estratégica caracterizada por articular e elaborar estratégias e visões já existentes, o pensamento estratégico refere-se a uma síntese que combina intuição e criatividade, resultando uma perspectiva integrada ou visão de direção não necessariamente articulada (WACK, 1998).

Mintzberg (1998) defende, então, a criação artesanal da estratégia em contrapartida ao desenvolvimento racional e deliberado de planos e padrões de ações. O autor entende que a imagem de uma criação artesanal da estratégia é a que melhor representa o processo de elaboração de uma estratégia eficaz. As estratégias podem combinar claramente a deliberação e controle com flexibilidade e aprendizagem organizacional. Sentimento, comprometimento e experiência são mais importantes do que a razão no processo de formulação da estratégia: "os processos de formulação e implementação transformam-se em um processo contínuo de aprendizagem através do qual surgem estratégias criativas" (MINTZBERG, 1998, p. 419). Os planejadores clássicos, muitas vezes, desconhecem o que estão planejando, desconhecem a sua própria organização e, por isso, tendem ao fracasso. O conceito mais básico da formulação estratégica está na conexão íntima entre pensamento $e$ ação. Isso é inevitável, diz o autor citado.

Percebe-se que o planejamento e a racionalização na formulação das estratégias são constantemente atacados por Mintzberg e por outros autores de estratégia. Porém, Goold e Campbell (1998) apontam que não existe uma maneira única e melhor de se formular estratégias. São atitudes que dependerão da natureza dos negócios de atuação, das pessoas envolvidas no processo, da necessidade de ação exigida pelo mercado, bem como dos objetivos e estrutura da organização. Goold e Campbell (1998) identificaram, em um estudo com 16 empresas britânicas, três estilos bem-sucedidos de formu- 
lação e condução de estratégias: "planejamento estratégico", "controle financeiro" e "controle estratégico".

O planejamento estratégico busca atingir metas mais ousadas por meio de planos devidamente definidos pelo alto escalão da corporação. Já no estilo controle financeiro, a responsabilidade das estratégias, bem como os esforços para atingi-las repousa sobre as unidades de negócio que ainda são orientadas por um forte controle orçamentário advindo do alto escalão da corporação. Nesse caso, há uma preocupação muito grande em evitar aumento de custos no processo estratégico. No modelo controle estratégico, busca-se reunir os pontos fortes dos dois estilos relatados anteriormente. Os gerentes definem estratégias com a participação constante do alto escalão da organização. Porém, as estratégias devem ser ousadas - buscando o crescimento da organização - e passíveis de controle financeiro por meio de um processo planejado e lógico.

Portanto, o que se entende dos modelos apresentados é que o planejamento ainda tem participação significativa na formulação de estratégias, de acordo com as observações de Goold e Campbell (1998). Entretanto, Wack (1998) acredita ser muito perigoso tentar prever uma situação futura em um contexto de instabilidade. Para ele, nenhuma projeção correta pode ser deduzida a partir do comportamento passado e a melhor abordagem é aceitar as incertezas. Mintzberg, Ahlstrand e Lampel (2000), afirmam que nenhuma estratégia do mundo real pode ser puramente deliberada ou emergente, uma vez que uma impede o aprendizado enquanto a outra impede o controle. Para esses autores, a pergunta a ser respondida é: que grau de cada uma é adequado, onde e quando? Portanto, passa-se a buscar compreender a importância de cada uma das formas de construção da estratégia, seja por planejamento, intuição, feeling, cognição e outros.

De acordo com os estudos de Vasconcelos (2001), os gestores organizacionais não adotaram nenhuma escola específica e preferiram montar suas estratégias recolhendo partes de cada uma delas, ou seja, não há defesa de única posição em relação à formação de estratégias e, sim, uma tentativa de acertar com o que encontra-se disponível. Mintzberg, Ahlstrand e Lampel (2000) novamente destacam a multiplicidade característica da estratégia e de sua construção quando comentam a escola da configuração.

A construção de estratégia pode ser feita a partir da concepção conceitual ou do planejamento formal; da análise sistemática ou da visão estratégica; do aprendizado cooperativo ou da politicagem competitiva; de cognição in- 
dividual ou de socialização coletiva ou ainda, simplesmente reativa ao ambiente (MINTZBERG; AHLSTRAND; LAMPEL, 2000).

A formação de estratégias nas organizações depende, portanto, da corrente teórica de maior influência nos gestores e da natureza, complexidade, competição e outros fatores que influenciam o ambiente de negócios. A formulação e implementação de estratégia devem considerar aspectos internos e externos da organização, localizados no ambiente, e recomenda-se buscar uma compatibilização entre esses dois conjuntos de elementos (MEIRELLES, 2003). Quanto aos aspectos internos, esse autor entende toda a organização como sua estruturação, hierarquização, políticas e poderes. A congruência das pessoas, os objetivos, o porte e os interesses serão sempre fontes de influência para a construção e desenvolvimento das estratégias.

A partir de reflexões sobre instituição, cultura, racionalidade e cognição, pode-se ver que, de uma forma ou de outra, a estratégia é construída na dinâmica cotidiana e, querendo ou não, por todos os atores organizacionais (MEIRELLES, 2003). A percepção dos vários fatores internos ou externos que compõem o sistema organizacional pode influenciar a formação da estratégia em uma organização. Portanto, faz-se necessário entender também quem é (são) o(s) responsável(is) pela criação e desenvolvimento de estratégias para assim identificar a influência dele(s) no processo. Mintzberg (2001) aponta para o executivo principal da empresa a responsabilidade estratégica da organização: a criação da estratégia, naturalmente, é responsabilidade do executivo principal e o processo tende a ser altamente intuitivo e, com frequência, orientado para a procura agressiva de oportunidades.

Não é de se surpreender, portanto, que a estratégia resultante tenda a refletir a visão implícita de que o executivo principal tem do mundo, muitas vezes uma extrapolação de sua personalidade. (MINTZBERG, 2001, p. 232)

A percepção das pessoas envolvidas e a comunicação da empresa em relação à estratégia sobre as forças competitivas poderão definir os rumos que a organização irá tomar no curto, no médio e no longo prazo.

Em relação aos aspectos externos, o ambiente será sempre o ponto de equilíbrio para a orientação estratégica que a organização irá assumir e, portanto, procura-se, na presente pesquisa, ater-se a essa discussão, desenvolvendo as informações específicas do caso proposto. Assim, a contribuição do trabalho se torna ainda maior por oferecer a outros pesquisadores uma opor- 
tunidade de identificar os fatores macroambientais que têm poder direto sobre a construção estratégica de uma empresa.

\section{Metodologia}

Este trabalho é caracterizado, principalmente, pela utilização da metodologia qualitativa de pesquisa. Para Vieira e Zouain (2004, p. 17)

[...] a pesquisa qualitativa pode ser definida como a que se fundamenta principalmente em análises qualitativas, caracterizando-se em princípio, pela não utilização de instrumental estatístico na análise dos dados.

Lüdke e André (1996) afirmam que a pesquisa qualitativa exige do pesquisador um contato real e em profundidade com o ambiente e o cenário que está sendo investigado. Além disso, a pesquisa qualitativa auxilia o pesquisador a adequar seu conteúdo teórico ao problema de pesquisa, no decorrer do processo.

Quanto aos fins, segundo a classificação de Gil (2002), esta pesquisa pode ser considerada descritiva. A partir dos prévios conhecimentos do tema de estudo, partiu-se para a descrição de atitudes que são tomadas como estratégias por um grupo de empresas pertencentes ao segmento foco de estudo. O pesquisador parte de uma ideia e aprofunda seu estudo nos limites de uma realidade específica, buscando antecedentes e maior conhecimento para, em seguida, planejar uma pesquisa descritiva e definir seu roteiro de investigação (TRIVINOS, 1987).

No entanto, o método predominante e característico do trabalho foi o estudo de caso, o que possibilitou um levantamento mais completo de informações e um aprofundamento da investigação. O estudo de caso é apresentado por Vergara (2003) como metodologia direcionada para o conhecimento em profundidade de uma determinada problemática e tem como maior limitação a impossibilidade de generalização dos resultados para outras empresas. Porém, apresenta como grande vantagem o fato de os dados levantados representarem de forma mais completa a realidade da pesquisada.

O presente estudo teve como foco de investigação as grandes empresas produtoras de carne de frango localizadas no Estado de Minas Gerais. Le- 
vando em conta o elevado número de empresas que atendem ao requisito inicial e às consequentes dificuldades para o pesquisador investigar todas as grandes empresas, definiu-se a empresa Alfa como caso específico de estudo.

A empresa Alfa preenche os requisitos básicos do caso a ser estudado porque é uma grande empresa produtora e distribuidora de carne de frango, que se encontra em desenvolvimento no mercado interno e externo, passa por um período de ampliação de sua estrutura física e humana, possui notoriedade em seu mercado de atuação, demonstrou interesse por esta pesquisa e possui uma administração profissional (considerando que vem compondo suas gerências com técnicos dotados de aptidões específicas para o exercício das atividades a serem desempenhadas nos departamentos e, ainda, que não fazem parte da família proprietária da organização).

As unidades de observação pesquisadas foram as pessoas que ocupam cargos de alta gerência na empresa, que tem uma estrutura gerencial e de direção relativamente enxuta: são dois diretores - proprietários da empresa e oito gerentes que têm participação direta nas decisões estratégicas. Esse grupo de diretores e gerentes são os atores mais adequados para responder às questões referentes às mudanças $e$ decisões estratégicas que norteiam o desenvolvimento organizacional. Ao todo, foram entrevistados sete gerentes e um diretor.

Os dados foram coletados por meio de entrevistas semiestruturadas. A escolha dessa técnica é justificada por possibilitar uma interação maior entre o pesquisador e os pesquisados. Conforme Lüdke e André (1996, p. 33), "na entrevista a relação que se cria é de interação, havendo uma atmosfera de influência recíproca entre quem pergunta e quem responde".

As entrevistas tiveram uma duração média de 50 minutos e foram realizadas ao longo de dois meses. Um pré-teste dos roteiros de entrevista foi realizado com o gerente de projetos da empresa, que foi então, excluído do grupo final. O tratamento dos dados consistiu, basicamente, de uma análise do conteúdo das entrevistas realizadas. Esse método é constituído por um conjunto de técnicas (classificação de conceitos, codificação e categorização) que permite estudar as comunicações entre os homens, enfatizando o conteúdo das mensagens. Para Bardin (1977), a análise de conteúdo é uma técnica que visa compreender o sentido de um texto. Portanto, as entrevistas foram transcritas para a realização da análise de conteúdo das mensagens e, então, realizadas as inferências a partir das informações obtidas. 
As análises estão identificadas por códigos que representam o cargo e departamento dos entrevistados. Assim, os oitos entrevistados são caracterizados da seguinte forma: gerência contábil/financeira (G1), gerência de recursos humanos (G2), gerência de segurança (G3), gerência de qualidade (G4), gerência de produção (G5), gerência Administrativa (G6), Gerência comercial (G7) e Diretoria (D8).

\section{Análise e Discussão dos Resultados}

A construção da estratégia de uma organização pode seguir processos distintos e, às vezes, antagônicos. Alguns autores defendem que a construção da estratégia de uma empresa segue o seu padrão gerencial para todas as outras decisões (WHITTINGTON, 2002), enquanto outros autores entendem que a formação da estratégia dependerá de fatores externos, como o próprio ambiente (MINTZBERG, 2001). O que se pode afirmar é que a formação ou construção da estratégia organizacional é algo íntimo da empresa, que dependerá das decisões internas e do posicionamento da diretoria e dos gestores.

Na pesquisa, foi constatado que a empresa Alfa tinha uma formação familiar, centralizada e que passava por um rápido processo de crescimento. Isso aponta para uma empresa ainda não estruturada para a estratégia, mas que já compreende a importância de se utilizar tais processos para acelerar seu desenvolvimento. Os depoimentos colhidos sustentam essa impressão:

Nós ainda não planejamos muito e eu acho que a estratégia depende do planejamento. Mas nós temos objetivos a serem executados. E isso leva todos para o mesmo lugar. Além disso, acho que a grande virtude da empresa é o conhecimento, a visão que temos do nosso negócio. Essa é a nossa grande estratégia por enquanto...(G1)

Desde que entrei na empresa, os setores e até mesmo a diretoria vêm sofrendo modificações importantes. A empresa iniciou seu processo de forma artesanal e as mudanças não podem ser muito abruptas. Mas nos últimos anos eles (donos) vem profissionalizando a empresa e eles mesmos. Estão passando de donos para diretores. (G5) 
A empresa não atua ainda com planos de estratégia formalizados, mas certamente ela trabalha com estratégias. Estratégias em busca de oportunidades de crescimento. (G6)

Acho, sim, que a empresa valoriza a estratégia. Até porque a empresa está em crescimento e então, se a empresa não der valor às estratégias, em planos, em organização, ela não progride. (G3)

A gente percebe a estratégia de duas formas: primeira como forma de sobrevivência - a curtíssimo prazo pensamos na estratégia como questão de sobrevivência. E numa segunda etapa, como forma de crescimento. (D8)

Essas análises preliminares demonstram uma preocupação da empresa em utilizar a estratégia como suporte para o crescimento, o desenvolvimento $e$ até mesmo a sobrevivência. Além da compreensão do padrão estratégico da empresa, as análises apontam para a principal discussão deste trabalho: a formação da estratégia. Vários gerentes entendem que a estratégia possui uma dependência do planejamento. A estratégia seria então baseada em planejamento e com objetivo direto de maior lucratividade. Essa visão clássica - conforme a classificação de Whittington (2002) - se apresenta nos discursos dos gerentes. Porém, quando se buscou identificar como a estratégia acontece de fato, o planejamento perdeu parte da sua força e as respostas remeteram a um processo mais emergente e que busca resultados plurais - não apenas uma maior lucratividade, mas também sobrevivência, desenvolvimento tecnológico, imagem social e outros, tudo isso condiz com a escola processual definida por Whittington (2002).

A estratégia da empresa Alfa pode ser também definida como emergente dentro da abordagem de Mintzberg (2001). O autor procura identificar se a estratégia é baseada em planos (deliberada) ou se acontece em resposta ao ambiente (emergente). Nesse caso, fica claro que a maioria das estratégias da empresa Alfa acontece como resposta aos fatores e influências ambientais, apesar de que essa característica é sempre relacionada com a improvisação, com pouca profissionalização da organização ou com ambientes turbulentos. Os depoimentos de três dos entrevistados são claros a esse respeito:

A nossa estratégia é formada assim: a maior parte é em resposta ao ambiente. Eu acho que a primeira reação nossa é isso. O Ambiente está te pedindo, alguém está te cobrando alguma coisa e 
você tem que agir para corrigir aquilo ou pra atender à exigência. E com o tempo a gente vai aprimorando as nossas atitudes para facilitar o nosso trabalho. Aí sim, iremos desenvolver algo para atender as empresas clientes e a nossa também. (G4)

Hoje, ainda, eu acho que até pode ser modificado nas cadeias, mas hoje ainda nós temos setenta por cento das estratégias como resposta do ambiente e 30 por cento como planejamento. Dentro dessa mudança, até mesmo de visão dos diretores da empresa, nós temos planejado trinta por cento das nossas ações. Como exemplo, a busca da empresa pelo mercado europeu. Essa busca de ampliação do mercado está dentro de uma estratégia que a empresa quer executar sem ter resposta ainda do ambiente, sem ter cobrança de nada. Mas, como a cadeia da avicultura varia muito durante o ano, temos que dar um passo a frente e nos adiantar. Então, a maior parte das estratégias requer resposta de imediato. Se fosse com um ano, com um ano e meio, que nem são os outros trinta por cento que a gente já planeja, não estaríamos trabalhando com tanta resposta do ambiente. (G5)

Percebo que a estratégia era uma necessidade do ambiente. Necessidades externas à empresa. E aí as coisas iam acontecendo. E de um tempo pra cá, a partir da conquistas, principalmente de mercados externos, ampliação da empresa, eu acho que está surgindo mais esta demanda de se planejar pra se atingir alguns objetivos específicos. Mas isto eu acho que vem assim, de uns dois, no máximo três anos pra cá. Eu acho que é isto é que tem alavancado tanto o crescimento. Hoje existe uma gerência de produção que tem engenheiros de alimentos, veterinários. Outras áreas também possuem pessoas técnicas. De uma maneira geral, está acontecendo uma profissionalização da empresa, que eu acho que é o resultado dessa mudança e desse planejamento pra atingir melhorias. (G2)

A construção da estratégia na empresa Alfa se mostra ainda muito mais como uma resposta aos movimentos do ambiente do que algo devidamente deliberado. Deve-se compreender o que leva a empresa a ter tal posicionamento em relação ao seu processo de formação de estratégias. Esse posicionamento é, muitas vezes, consequência de seu processo gerencial ou 
influenciado diretamente pelo perfil de seus criadores. A criação da estratégia, naturalmente, é responsabilidade do executivo principal e o processo tende a ser altamente intuitivo, com frequência orientada para a busca agressiva de oportunidades. Não é de surpreender, portanto, que a estratégia resultante tenda a refletir a visão implícita de que o executivo principal tem do mundo, muitas vezes, uma extrapolação de sua personalidade, conforme sustenta Mintzberg (2001). Dois outros depoimentos apontam para tal conclusão:

Então a alta direção fala o seguinte: nós queremos chegar onde houver consumo de frango no planeta. Então essa é a estratégia da diretoria. Nós queremos ser os melhores. Ou sermos os maiores! Então o restante da empresa e todos os departamentos juntos, concentrarão seus esforços para atender aos objetivos estabelecidos pela diretoria. Portanto, a estratégia vem da direção e, no nível micro, cada departamento desenvolve suas ações para atender aos anseios da direção. Enfim, entendo que a estratégia é muito mais emergente - surge de uma pressão do ambiente e que é rapidamente percebida pelos diretores - do que deliberada. Entendo que o planejamento ocorre no nível micro, ou de cada setor. (G7)

Além de outros fatores que nos forçam a desenvolver nossas estratégias de forma não-planejada, temos uma pressão forte que é o poder central de decisões. Os diretores são os pontos centrais nas decisões e, portanto, trabalhamos para atender aos pedidos dos executivos. Não que isso seja ruim, mas é um limitador de nossas ações de médio e longo prazo que poderiam ser executadas por meio de um plano estruturado. (G4)

Alguns autores apontam para uma tendência mista entre os processos de construção de estratégias. Normalmente, as empresas seguirão caminhos distintos quando o ambiente apresentar cenários diferentes. Assim, a construção das estratégias não seria um processo definitivo e, sim, flexível ao contexto ambiental, o que remete novamente ao trabalho de Vasconcelos (2001). Na verdade, cabe aos administradores definirem o momento em que deve ser adotada cada uma das possibilidades de construção e desenvolvimento de estratégias. Essa postura é explicada, muitas vezes, por um ambiente instável e de mudanças extremamente rápidas, com um mix de fatores que in- 
fluenciam diretamente nos resultados organizacionais. É o que sugerem os depoimentos dos seguintes entrevistados:

Acho que a gente dá mais uma resposta às necessidades do que qualquer outra coisa. Entendo que damos respostas contínuas ao mercado. Ele (mercado) nos apresenta suas necessidades e nós temos que nos adaptar às novas situações geradas... as coisas acontecem rápido demais aqui na empresa. Por isto nós não podemos ter planejamento. Só quem está aqui sabe o que estou dizendo. Com mudanças tão contínuas, não há possibilidade de se programar nada. Mas devemos ficar atentos a tudo para acompanhar o ambiente. (G1)

As estratégias acontecem de duas formas. Às vezes ela emerge, às vezes ela é planejada. Ela é planejada quando o tempo de retorno é maior, ou seja, de longo prazo. E ela é emergente quando temos que responder alguma coisa em curto prazo. Como o nosso negócio está inserido em um ambiente muito dinâmico, grande parte de nossas ações estratégicas tem que ser de forma emergente, sem tempo para um plano formalizado. Se fizermos um plano longo demais, quando terminarmos, talvez as ações já não teriam nenhum valor. Temos que acompanhar o que o mercado pede. (G6)

Na verdade, eu acho que ela emerge do ambiente. Talvez não seja o modelo ideal. Talvez fosse importante a empresa estar um passo a frente, trabalhar com planejamento. Mas entendo que hoje, dentro de nossa organização e dentro do segmento que atuamos, a nossa estratégia emerge. O que o meu concorrente está fazendo? O que o meu cliente está fazendo? Então, vamos analisando o ambiente e ele nos empurra para as respostas rápidas e sem planos formais... (D8)

Avaliar qual processo ou qual abordagem é a ideal não é o objetivo deste trabalho, mas, a partir do depoimento de um gestor (D8), percebe-se que há uma preocupação em se chegar a um modelo ideal. Nesse caso, o que se busca é identificar como a empresa constrói sua estratégia e quais implicações existem para cada modelo. Se existe um processo ideal para cada empresa, ele somente poderá ser definido a partir de outros estudos que ava- 
liem e comparem também os resultados dentro de um período pré-determinado. Os principais autores utilizados neste trabalho acreditam que a construção da estratégia se dá em uma combinação de ações e de perspectivas, baseado principalmente em influências do ambiente. Como sugerem Mintzberg, Ahlstrand e Lampel, (2000), estratégia pode ser construída a partir da concepção conceitual ou do planejamento formal; da análise sistemática ou da visão estratégica; do aprendizado cooperativo ou da politicagem competitiva; de cognição individual ou de socialização coletiva ou ser simplesmente uma reação ao ambiente.

Diante disso, pode-se concluir que a estratégia na empresa Alfa é construída a partir de respostas às necessidades do ambiente e, quando possível, ela é baseada em planejamento estruturado ou na adoção de procedimentos mais claros e racionais e com mecanismos de controle e avaliação. Mais uma vez pode-se remeter ao argumento de que é claro que a combinação das técnicas de construção de estratégias - emergente quando necessário e deliberada quando possível - se torna o modelo ideal para as organizações. De acordo com Mintzberg, Ahlstrand e Lampel (2000), nenhuma estratégia do mundo real pode ser puramente deliberada ou emergente, uma vez que uma impede o aprendizado, enquanto a outra impede o controle. Assim, a pergunta passa a ser: que grau de cada uma é adequado, onde e quando?

\section{Conclusão e Implicações Gerenciais}

A empresa Alfa passa por um forte período de transição que inclui profissionalização de suas operações e gestão, expansão de mercado e da sua estrutura física, maior amplitude de sua marca e outros. Todas as mudanças são de extrema importância para a organização, mas trazem certa resistência das pessoas envolvidas (TAVARES, 2005).

Pode-se concluir com este trabalho que a estratégia é, ainda, para a empresa alfa, uma função ocasional, reativa ao ambiente, emergente de acordo com as necessidades mercadológicas. Não que as pessoas não valorizem a estratégia, mas não existe uma filosofia própria de criação estratégica planejada e deliberada. Essa prática se confunde com o discurso das pessoas envolvidas nesta pesquisa. A maioria dos gerentes entrevistados relata sua percepção clássica (processo racional, baseado em planos e com objetivos de maximização de lucro) sobre a estratégia e destaca a importância da con- 
secução e dos processos de estratégias para o desenvolvimento da empresa. Porém, na prática, observa-se outra realidade. A estratégia continua sendo importante para a empresa, mas de maneira processual (baseada em rápidas respostas reativas às oscilações e demandas ambientais, buscando objetivos variados), emergente, sem um planejamento formal e estruturado. Há na verdade uma tentativa de se construírem estratégias deliberadas, mas que isso é minoria de acordo com os gerentes participantes da pesquisa.

As justificativas são inúmeras, mas, em sua grande maioria, vêm de encontro à velocidade de mudança do mercado, às inserções de mudanças tecnológicas do setor, à forte concorrência e, principalmente, ao crescimento da empresa. Todos esses fatores explicam a necessidade e o posicionamento da empresa Alfa em relação à estratégia. Há que se admitir que a empresa busca constantemente inserir planejamentos de médio e longo prazo, com formalização dos processos, com envolvimento das pessoas de cada setor, da diretoria, buscando atingir resultados significativos. Mas nem sempre é possível manter tais planos de maneira concreta e sem grandes adaptações. Isso, porque o segmento é dinâmico e a empresa saiu de um ciclo de pequenos crescimentos e aponta para uma participação cada vez maior no mercado nacional e internacional. Portanto, ela busca mesclar sua construção estratégica entre as formas deliberada e emergente, sendo a última preponderante no seu dia a dia.

Os resultados operacionais continuam sendo os principais pontos de referência para a avaliação e a ideia de uma estratégia formal, planejada, continua sendo uma meta da organização. Na verdade, a empresa se adapta ao seu ambiente e constrói sua estratégia a partir do que o ambiente lhe proporciona: planejado apenas quando há tempo e estrutura para isso e emergente quando o ambiente obrigar. De acordo com Mintzberg, Ahlstrand e Lampel (2000), a construção de estratégia pode ser feita a partir da concepção conceitual ou do planejamento formal; da análise sistemática ou da visão estratégica; do aprendizado cooperativo ou da politicagem competitiva; de cognição individual ou de socialização coletiva ou, ainda, simplesmente reativa ao ambiente.

Recomenda-se, a partir deste trabalho, que novas pesquisas relacionadas à construção de estratégias sejam realizadas, utilizando este estudo e outras metodologias como referência, de modo que os pesquisadores possam oferecer resultados generalizados ao segmento. No caso específico desta pesquisa, não foi objetivo produzir nenhum tipo de generalização, mas, sim, um 
estudo aprofundado da realidade de uma empresa da indústria avícola em relação ao processo de construção de suas estratégias, o que explica a metodologia empregada no trabalho. Porém, o estudo se valorizará se, a partir dele, novas investigações forem realizadas para a geração de conhecimentos empíricos sobre a atuação e atitudes em relação às estratégias na indústria avícola e outras indústrias correlatas. Portanto, um estudo que envolva um maior número de empresas e que possa atender à generalização seria a principal recomendação deste trabalho.

É importante ressaltar que o resultado encontrado nesta pesquisa pode sim ser um indicador da realidade de muitas empresas do segmento, colocando em dúvida, a funcionalidade de inúmeros sistemas e programas de gestão, que oferecem melhores resultados por meio de processo longos e complexos de planejamento. Não é intenção criticar nenhum programa ou projeto, mas sim, levantar, a partir destes resultados, uma discussão sobre a usabilidade de programas que exijam das organizações aquilo que elas não podem ou não estão preparadas a executar.

\section{The Strategies Construction: a study case in the poultry sector}

\section{Abstract}

This paper aims to study the process of formulating strategies in a poultry sector company in the state of Minas Gerais. The objective was to verify if the company built its strategies deliberately - relying on the traditional conception of strategy or in an emergent way, as a response to the movements of the environment. Methodologically, the research was qualitative in nature, with descriptive goal and supported by a case study in which eight managers of Alfa company were interviewed using a semi-structured guide. The content analysis of the interviews indicates that Alfa company, still has as standard formulating strategies like responses to the environment, despite the efforts to implement deliberated processes of construction. The plans and rational processes of building strategies, although they are considered of great importance by the interviewees, were not present in the company daily. That research results are relevant to the Administration area due to two reasons: The first one is to indicate that the strategy - in the case of the investigated company - is made mainly based on reactions to the environment and not as a result of a rational process of analysis and definition. The second one is to indicate that the managers know the importance of these more rational 
processes of strategies elaboration, but that several factors prevent them from being applied in practice.

Key words: Strategy. Competitivity. Formulation. Decision making. Results.

\section{Referências}

ABEF - Associação Brasileira dos Produtores e Exportadores de Frangos. Relatório anual 2008/2009. Disponível em: <www.abef.com.br>. Acesso em: $1^{\circ}$ dez. 2009.

ANSOFF, H. I.; MCDONNELL, E. Implantando a administração estratégica. 2. ed. São Paulo: Atlas, 1993.

BARDIN, L. Análise de conteúdo. Lisboa: Edições 70, 1977.

CLEGG, S.; CASTER, C.; KORNBERGER, M. A máquina estratégica: fundamentos epistemológicos e desenvolvimentos em curso. In: RAE - Revista de Administração de empresas. v. 44, n. 4, out. a dez., 2004. FGV: São Paulo, 2004b.

GIL, A. Como elaborar projetos de pesquisa. 4. ed. São Paulo: Atlas, 2002.

GOOLD, M.; CAMPBELL, A. As melhores maneiras de formular estratégias. In: MONTGOMERY, C. Estratégia: a busca da vantagem competitiva. 2. ed. Rio de Janeiro: Campus, 1998.

LÜDKE, M.; ANDRÉ, M. Pesquisa em Educação: abordagens qualitativas. São Paulo: EPU, 1996.

MATIAS, A.; MEIRELLES, J.; CALDEIRA, L.Estratégia, investimentos e competitividade da indústria avícola brasileira. In: SEMEAD, 6, 2002, São Paulo. Anais... São Paulo: FEA/USP, 2002.

MEIRELLES, A. A Formação de estratégia no sistema bancário brasileiro: modelo teórico e evidências empíricas. 2003. Tese (Doutorado em Administração) - Universidade Federal de Minas Gerais, Belo Horizonte. 
MINTZBERG, H. A criação artesanal da estratégia. In: MONTGOMERY, C. Estratégia: a busca da vantagem competitiva. 2. ed. Rio de Janeiro: Campus, 1998. p. $419-440$.

. O Processo da Estratégia. Porto Alegre: Bookman, 2001.

MINTZBERG, H.; AHLMSTRAND, B.; LAMPEL, J. Safári de Estratégia: um roteiro pela selva do planejamento estratégico. Porto Alegre: Bookman, 2000.

MINTZBERG, H.; WATERS, J. Of strategies, deliberate and emergent.

Strategic Management Journal, v. 6, p. 273-293, 1985.

PETTIGREW, A. Strategy formulation as a political process. International Studies of Management \& Organization, v. 7, n. 2, 1977.

PORTER, M. Vantagem competitiva: criando e sustentando um desempenho superior. Rio de Janeiro: Campus, 1989.

. What is strategy? Harvard Business Review, p. 61-78, 1996.

RIBEIRO, Maria T. F.; REZENDE, Daniel C.; REZENDE, Gustavo C. A Construção de estratégias competitivas no Agribusiness: combinando diferentes abordagens dinâmicas. In: ENANPAD, 24 , São Paulo: 2000.

SARAIVA, E. A Construção de estratégias: um estudo de caso no setor de telefonia móvel. Belo Horizonte. 2004. Dissertação (Mestrado em Administração) - Universidade Federal de Minas Gerais, Belo Horizonte.

SCHARDONG, G.; GONÇALO, C. Fatores Competitivos do setor de Avicultura no Brasil: uma análise da opção estratégica do grupo Doux. In: ENCONTRO DE ESTUDOS DE ESTRATÉGIA - 3Es, 2, 2005, Rio de Janeiro. Anais... Rio de Janeiro: Associação Nacional dos Programas de Pós-Graduação em Administração, 2005.

SEBRAE. Indicadores das MPEs 2008/2009. Disponível em: $<w w w . s e b r a e . o r g . b r>$. Acesso em: $1^{\circ}$ jul. 2009.

SOBANSKI, J. Prática de orçamento empresarial. 3. ed. São Paulo: Atlas, 1995.

TAVARES, M. Gestão Estratégica. 2. ed. São Paulo: Atlas, 2005. 
TRIVINOS, A. Introdução à Pesquisa em ciências sociais: a pesquisa qualitativa na educação. São Paulo: Atlas, 1987.

UBA - União Brasileira da Avicultura. Relatório anual 2004/2005. Disponível em: <http://www.abef.com.br/uba/arquivos/relatorio04_05.pdf > . Acesso em: 21 jul. 2010.

VASCONCELOS, F. Safári de estratégia, questões bizantinas e a síndrome do ornitorrinco; uma análise empírica dos impactos da diversidade teórica em estratégia empresarial sobre a prática dos processos de tomada de decisão estratégica. In: ENANPAD, 25, 2001, Campinas. Anais... Rio de Janeiro: Associação Nacional dos Programas de Pós-Graduação em Administração, 2001.

VERGARA, S. Projetos e relatórios de pesquisa em administração. São Paulo: Atlas, 2003.

VIERA, M.; ZOUAIN, D. (Org). Pesquisa qualitativa em Administração. Rio de Janeiro: FGV, 2004.

VOLBERDA, H. Crise em estratégia: fragmentação, integração ou síntese. Revista de Administração de empresas, São Paulo, v. 44, n.4, 2004.

WACK, P. Cenários: águas desconhecidas à frente. In: MONTGOMERY, C. Estratégia: a busca da vantagem competitiva. 2. ed. Rio de Janeiro: Campus, 1998. p. 363-394.

WILSON, D.; JARZABKOWSKI, P. Pensando e agindo estrategicamente: novos desafios para a análise estratégica. In: Revista de Administração de empresas, São Paulo, v. 44, n. 4, 2004.

WHITTINGTON, R. O que é Estratégia? São Paulo: Thomson, 2002.

WHITTINGTON, Richard. Estratégia após o modernismo: recuperando a prática. In: RAE - Revista de Administração de Empresas, v. 44, n. 4, out./dez., 2004. FGV: São Paulo, 2004a.

WHITTINGTON, Richard. National innovation and transnational variation. Keynote presentation, European Academy of Management, Bocconi University, April, 2003. 